\title{
JOINING SIC-BASED CERAMICS AND COMPOSITES WITH PRECERAMIC POLYMERS
}

Paolo Colombo

Dipartimento DICASM, Università di Bologna, Viale Risorgimento 2, 40136 Bologna, Italy and Department of Materials Science and Engineering, The Pennsylvania State University, University Park, PA 16801

A. Donato and B. Riccardi Associazione EURATOM-ENEA, ENEA CR Frascati, Via E. Fermi, 27, Frascati (Roma) 00044, Italy

J. Woltersdorf and E. Pippel

Max-Planck Institut für Mikrostrukturphysik, Weinberg 2, D-06120 Halle, Germany

R. Silberglitt* and G. Danko\$

FM Technologies Inc., Fairfax, VA 22032

C. Lewinsohn ${ }^{\mathfrak{E}}$ and R. Jones

Pacific Northwest National Laboratory, Richland, WA 99352

\begin{abstract}
Monolithic $\mathrm{SiC}$ bodies (sintered $\mathrm{SiC}$, reaction bonded $\mathrm{SiC}$ ) were successfully joined using a silicone resin. Maximum values as high as $220 \mathrm{MPa}$ in bending and about $50 \mathrm{MPa}$ in shear tests were reached for samples joined at $1200^{\circ} \mathrm{C}$. $\mathrm{SiC} / \mathrm{SiC}_{\mathrm{f}}$ composites were also joined using a silicone resin or a polycarbosilane and various fillers. In this case, the strength of the joints was much lower, increasing only when specific fillers or reinfiltration of the joints were employed. The reason for the lower strength possessed by $\mathrm{SiC} / \mathrm{SiC}_{\mathrm{f}}$ joints was attributed to the surface morphology of the composites.
\end{abstract}

\section{INTRODUCTION}

Silicon carbide is an important engineering ceramic because of its high strength and stability at elevated temperatures, and it is currently fabricated also in the form of a ceramic matrix composite, using $\mathrm{SiC}$ fibers as reinforcement. $\mathrm{SiC} / \mathrm{SiC}_{\mathrm{f}}$

\footnotetext{
* now with RAND, Arlington, VA 22202, USA

$\$$ now with Pratt and Whitney, East Hartford, CT 06108, USA

${ }^{£}$ now with Ceramatec Inc., 2425 South 900 West, Salt Lake City, Utah 84119, USA
} 
composites, in particular, have attracted a strong interest as components for the "first-wall" in a fusion energy system. In fact $\mathrm{SiC} / \mathrm{SiC}_{\mathrm{f}}$ composites possess the thermal, mechanical, and nuclear stability necessary for the application in the field of nuclear fusion [1]. When considering joining of a $\mathrm{SiC} / \mathrm{SiC}_{\mathrm{f}}$ composite, certain additional issues arise due to the use of composite as opposed to monolithic silicon carbide: specifically the degradation of fibers at an elevated temperature (determined by the type of fiber), the oxidation of the fiber-to-matrix interphase (in the presence of oxygen), and the surface roughness and porosity associated with the presence of the reinforcement within the ceramic matrix. Therefore, a method allowing joining of $\mathrm{SiC}_{\mathrm{SiC}}$ parts, but without compromising the overall properties that are needed, is required. For joining SiC-based ceramics, including composites, direct diffusion bonding, brazing, co-densification of green bodies and binders, reactive metal bonding, pressurized combustion reactions, in-situ displacement reactions, glassy interlayers, and reaction bonding techniques have been used, with various degrees of success [2, 3]. Generally speaking, diffusion bonding requires elevated temperatures (not compatible with the retention of fiber strength in composite materials) or pressures, while active metal brazing tends to create complex reaction layers which sometimes exhibit poor thermo-mechanical properties. The use of preceramic polymers for joining SiC-based ceramics has been proposed in the recent literature [4-13]. Indeed, the use of preceramic polymers for joining offers a number of attractive features, such as easy application, low processing temperatures and possibility to tailor the joint composition by adding suitable fillers to the preceramic precursor, but nevertheless several issues remain to be addressed and some specific problems still need to be solved. Preceramic polymers are organoelement polymers, generally containing silicon, which undergo a polymer-to-ceramic conversion when heated at temperatures ranging from 800 to $1400^{\circ} \mathrm{C}$. In order to maintain the shape of the preformed body, the polymer, if not thermosetting itself, must be cross-linked, either by oxidation, e-beam or radiation curing. The pyrolysis of cross-linked polymers is accompanied by the formation of gaseous reaction products, high volume shrinkage and a pronounced density increase [14]. When the pyrolysis temperature is below about $1400^{\circ} \mathrm{C}$, the produced material can be classified as an amorphous covalent ceramic, which usually transforms into a nanostructured crystallized ceramic at higher temperatures [15].

\section{EXPERIMENTAL}

Three types of SiC-based ceramics were used in the joining experiments: 1) hot pressed $\alpha$-SiC (cylindrical specimens with a diameter of $13 \mathrm{~mm}$ and a thickness of $4 \mathrm{~mm}$, containing $0.5-1 \%$ of either $\mathrm{Al}$ or $\mathrm{B}$ as sintering aid and having a porosity of $3 \%$, fabricated by ENEA); 2) reaction bonded $\mathrm{SiC}$ (SiSiC, bars 76x7x6 mm; HD530, Norton Company, Worcester, MA, consisting mainly of $\alpha$-SiC crystals 
with a bimodal grain size distribution (approximately 10 and $100 \mu \mathrm{m}$ ) embedded in a free silicon phase (23 vol. \%), with a density of $3.02 \mathrm{~g} / \mathrm{cm}^{3}$ and an open porosity less than $1 \%$ ); 3 ) $\mathrm{SiC} / \mathrm{SiC}_{\mathrm{f}}$ composites (two different $\mathrm{SiC} / \mathrm{SiC}_{\mathrm{f}}$ composites (2D and 3D) produced by SEP, a division of Snecma (Saint-Medard-en-Jalles, France) were used. They consist of a bi-directional cloth (CERASEP N2-1) and of a tri-dimensional weave (CERASEP N3-1) of Nicalon fibers densified by chemical vapor infiltration (CVI). The monolithic ceramics were polished on one side using a $5 \mu \mathrm{m} \mathrm{SiC} \mathrm{paper} \mathrm{(achieving} \mathrm{a} \mathrm{roughness} \mathrm{of} \sim 0.1 \mu \mathrm{m}$ ), and ultrasonically cleaned in acetone prior to joining. Original $\mathrm{SiC} / \mathrm{SiC}_{\mathrm{f}}$ composite specimens (cut into 10x8x3 mm coupons for the joining experiments) had a rather complex surface morphology (roughness $\mathrm{Ra} \sim 15-25 \mu \mathrm{m}$, average peak-to-valley height $\mathrm{Rz} \sim 100$ to $150 \mu \mathrm{m}$ ). Direct joining of as-received specimens (joining taking place on the coupons' main surface) was never successful, because the rough surfaces contain cavities in which the preceramic polymer is subjected to a large shrinkage upon pyrolysis, and the resulting defects in the ceramic layer behave as crack initiation sources [9].

In order to improve the surface quality, the composite specimens were thus mechanically polished on one side, using $\mathrm{SiC}$ and diamond paper, and ultrasonically cleaned in acetone prior to joining. After this procedure, the total roughness of both materials (measured on an area a few square millimeters wide) was greatly reduced. After grinding, the $\mathrm{SiC} / \mathrm{SiC}_{\mathrm{f}}$ composite's surface was comprised of flat areas (a few hundred $\mu \mathrm{m}^{2}$ wide) and of deep "valleys" where the fibers are interwoven. The surface roughness, measured only on the flat areas where joining mainly takes place, was of the order of $0.25-0.5 \mu \mathrm{m}$. It has to be pointed out that the $\mathrm{SiC} / \mathrm{SiC}_{\mathrm{f}}$ composites have a thick $\mathrm{SiC}$ over-coat $(>100 \mu \mathrm{m})$ deposited by CVD, which was not completely removed by the mechanical surface preparation. Thus the fibers were not exposed and did not participate to the joint formation. The real area of contact (flat zones) is smaller than the nominal one, typically of the order of 60 to $80 \%$ for the $3 \mathrm{D}$ composite specimens $[9,11]$.

The preceramic polymers used in the joining experiments were: a methylhydroxyl-siloxane (SR350, General Electric Silicone Products Div., Waterford, NY) and two polycarbosilanes (PCS, Dow Corning X9-6348, and allylhydridopolycarbosilane (AHPCS, Starfire Systems, Watervliet, NY). In some cases, the polymers were loaded with a monomodal or a bimodal powder mixture ( $\mathrm{SiC}$ or $\mathrm{Si}$ nano and micro powders, $\mathrm{Al}_{88}-\mathrm{Si}_{12}$ alloy, ) or with ceramic fibers and cloths (plane weave carbon or Nicalon (SiC) fiber cloth, carbon or Nicalon fibers impregnated with SR350 resin, carbon felt impregnated with SR350 resin). The polymers were dissolved in suitable solvents, and the viscosity of the solution was varied by changing the amount of solvent and of fillers. The viscous solutions were applied to the specimens to be joined using a spatula, and the samples were 
then overlapped obtaining a sandwich structure. In the case of reaction bonded $\mathrm{SiC}$, butt joints were also produced by cutting the overlapped joined specimens. In some cases, a crosslinking step by heating at $150-200^{\circ} \mathrm{C}$ in air was applied to cure the preceramic polymer. Reinfiltration experiments were also performed, using a diluted polymer solution without additives. After the infiltration in a vacuum container, the specimens were pyrolyzed, and the cycle was then repeated a few times. No pressure was applied during the thermal treatment.

Pyrolysis was conducted either by annealing in a conventional tube oven or by hybrid microwave heating, processing always in an inert atmosphere. The pyrolysis cycle (heating and cooling rate, maximum temperature, dwelling time) were varied in order to assess the influence of the processing parameters on the strength and quality of the joints. The experimental details for the morphological, microstructural, compositional and mechanical analyses performed can be found elsewhere $[5,9,10,11,13]$.

\section{RESULTS AND DISCUSSION}

The values of the fracture shear stress, measured at room temperature, for $\alpha$-SiC monolithic samples joined using a polysiloxane (SR350) and a polycarbosilane (PCS) at various temperatures are presented in Fig. 1a. The thickness of the joint, measured after the $200^{\circ} \mathrm{C}$ heat treatment, was $20 \pm 2 \mu \mathrm{m}$. First of all it is evident that, contrary to silicone resin, polycarbosilane does not serve an effective joining material, probably because of its different decomposition behavior upon pyrolysis (lower ceramic yield, thermosetting polymer) leading to the formation of defects in the joint. The shear strength increases with the joining temperature, and for samples pyrolyzed at $1200^{\circ} \mathrm{C}$ joined using the SR350 silicone resin, the most of the failures occurred not in the joint region but in the sintered $\alpha$-SiC body. Since the shear strength of ceramics is significantly lower than their tensile strength it is possible that the elastic mismatch between the joint material and the substrate generates a large stress intensification in the substrates near the interface. It is also possible that defects in the joint layer propagate into the higher modulus substrate and cause failure. Other reasons that might justify this behavior are flaws generated in the SiC substrate by clamping (that activate only when the joint strength is sufficient enough to transfer stress). Among the motives that explain the increase in shear strength of the joints increase with increasing joining temperature are the decrease of residual stresses in the joint with decreasing joint thickness due to the shrinkage of the pyrolysis product, the development of more $\mathrm{SiC}$-like species in the $\mathrm{SiOC}$ amorphous ceramic structure, and the densification of the polymer-derived ceramic material $[14,15]$.

The joining layer thickness strongly affected the joint strength (see Fig. 1b), in particular joint strength decreased with increasing joint thickness (thickness was measured before pyrolysis, after the crosslinking step. The joining material was 
SR350). In fact, evolution of gases and shrinkage during processing are identified as critical processes that may control the presence of strength limiting flaws and residual stresses. Computed values of the shrinkage stress for different combinations of shrinkage rate and viscosity indicate that shrinkage rates greater than $1 \times 10^{-4} \mathrm{~s}^{-1}$ and values of viscosity above $1 \times 10^{11} \mathrm{~Pa}-\mathrm{s}$ are required to generate significant values of stress $(>10 \mathrm{MPa})$ that may form cracks in the joints [13].
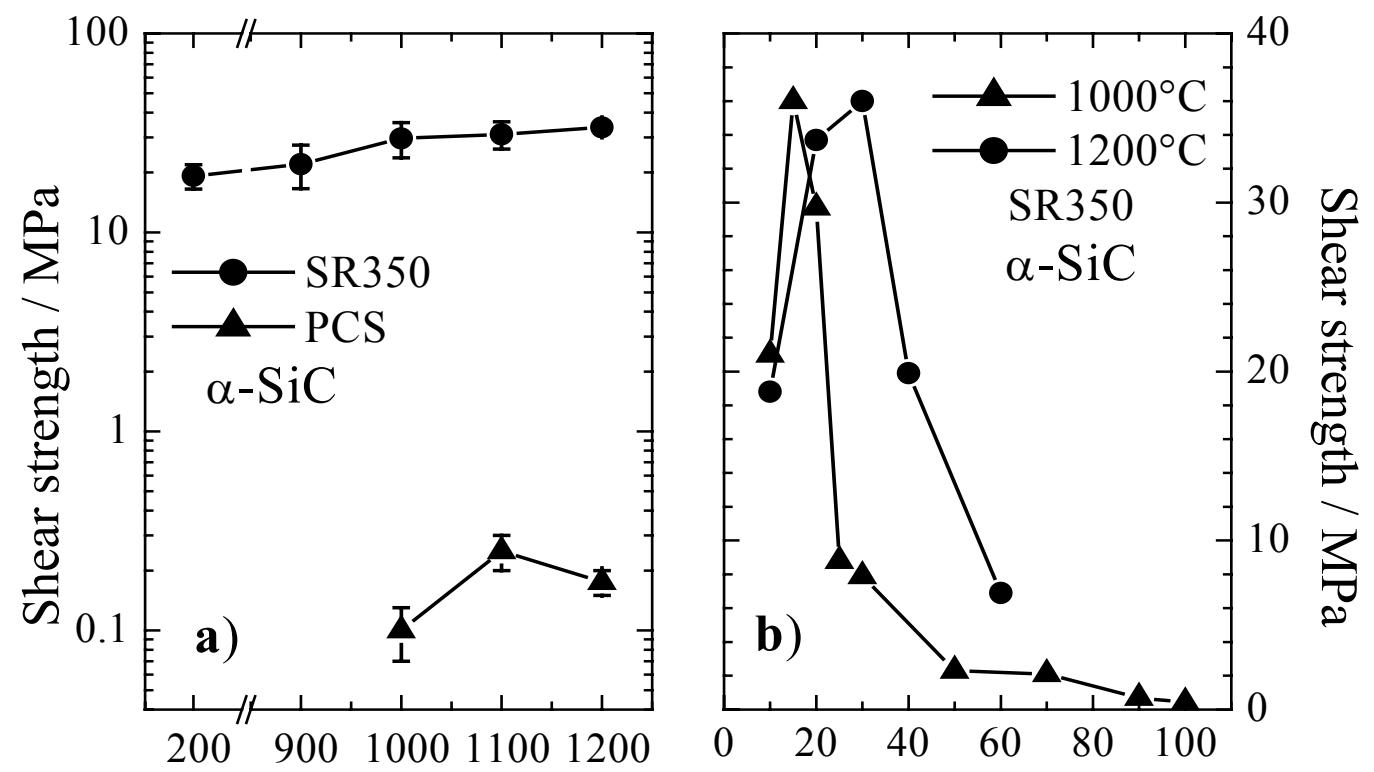

Joining temperature $/{ }^{\circ} \mathrm{C} \quad$ Joint Thickness @200 $20{ }^{\circ} \mathrm{C}$

Figure 1a. Shear strength as a function of joining temperature $(\alpha-\mathrm{SiC})$

Figure 1b. Shear strength as a function of joint thickness $(\alpha-\mathrm{SiC})$

Furthermore, the cooling rate and the joint thickness will influence the final stress state of a joint after cooling, with the residual stresses potentially leading to the formation of edge cracks, which may be avoided if the joint thickness is below a critical value [16].

Reaction-bonded SiC was also successfully bonded using SR350 polysiloxane. The flexural strength (butt joints) and shear strength, respectively, as a function of pyrolysis temperature are shown in Fig. $2 \mathrm{a}$ and $2 \mathrm{~b}$. High strength values can be obtained for processing temperatures higher than $1000^{\circ} \mathrm{C}$. Due to the similarity between the thermal expansion coefficient of the polymer-derived SiOC ceramic (approximately $3.14 \times 10^{-6} \mathrm{~K}^{-1}$ ) and of the $\mathrm{SiC}$ material, no major residual stresses were observed in the joints, as shown by the casual propagation of a crack, initiated by Vickers indentation, in the joint region [10]. 
Optical micrographs of SiSiC joined samples at different temperatures, showing the decrease of joint thickness due to the shrinkage of the pyrolysis product with increasing processing temperature, as well as the good quality of the joint (dense, continuous, without delamination or cracks), are shown in Fig. 3.

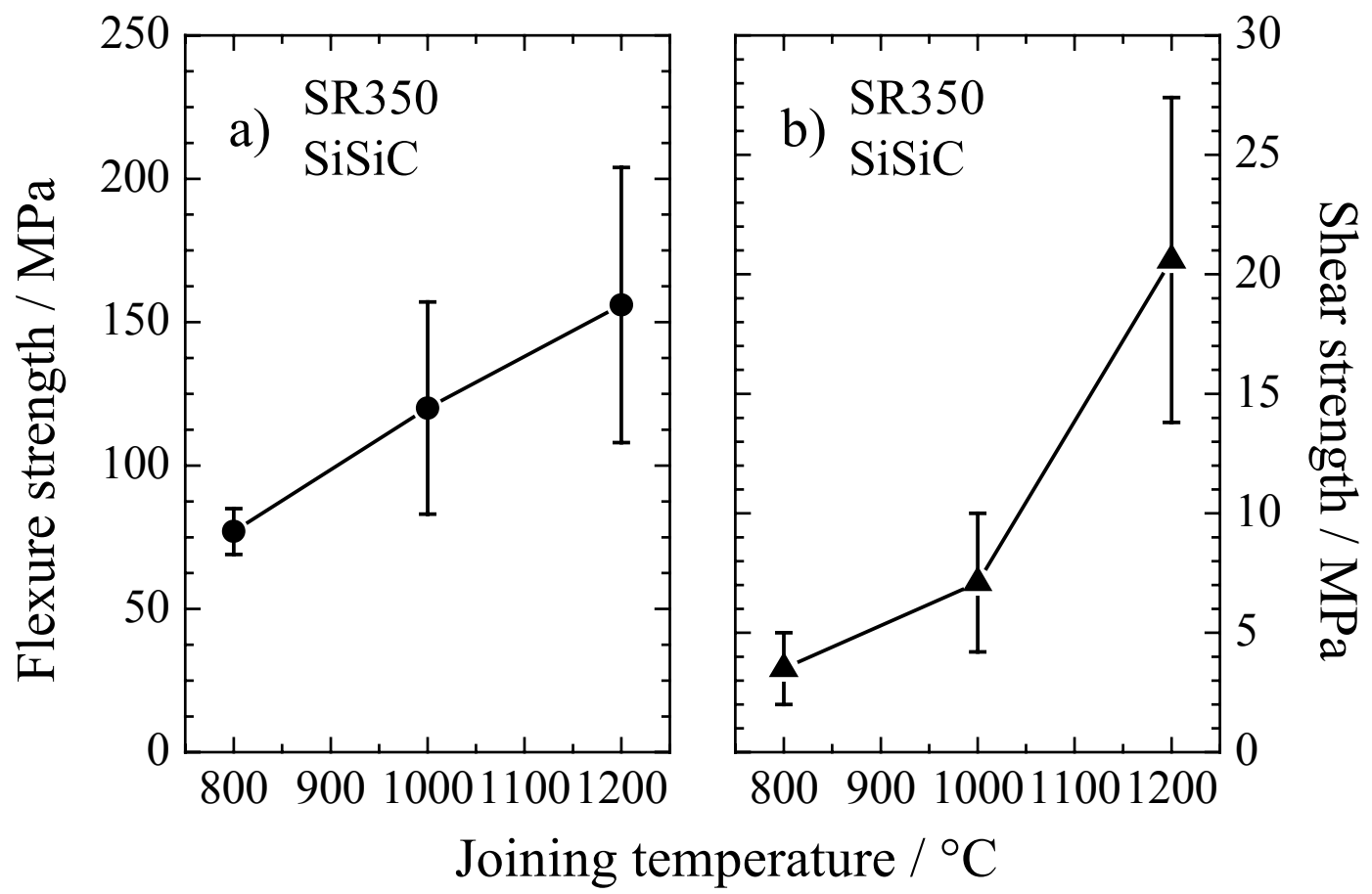

Figure 2a. Flexure strength as a function of joining temperature ( $\mathrm{SiSiC})$

Figure 2b. Shear strength as a function of joining temperature ( $\mathrm{SiSiC})$

$\mathrm{SiC} / \mathrm{SiC}_{\mathrm{f}}$ specimens were also joined using SR350 polysiloxane resin. An SEM micrograph indicating that while the joint, obtained by processing at $1200^{\circ} \mathrm{C}$, appears to be continuous, some voids are present due to the rough surface morphology of the ceramic composite is shown in Fig. 4a. The flat interface structure observed by high resolution electron microscopy (HREM) (Fig. 4b) and the lack of any reaction layer suggest a joining mechanism involving the direct formation of chemical bonds between the $\mathrm{SiC} / \mathrm{SiC}_{\mathrm{f}}$ bodies and the ceramic joining material, which consists in an amorphous SiOC ceramic. Microchemical analyses showed no oxygen diffusion occurring between the SiOC and the SiC ceramics [9].

For all types of SiC-based ceramic substrates used, the mechanism of failure was cohesive, since traces of the pyrolyzed polymer could be found on each surface that had been joined. This indicates the formation of a strong adhesive bond 
between the substrate and the preceramic-derived ceramic material as well as the presence of a limited amount of residual stresses.
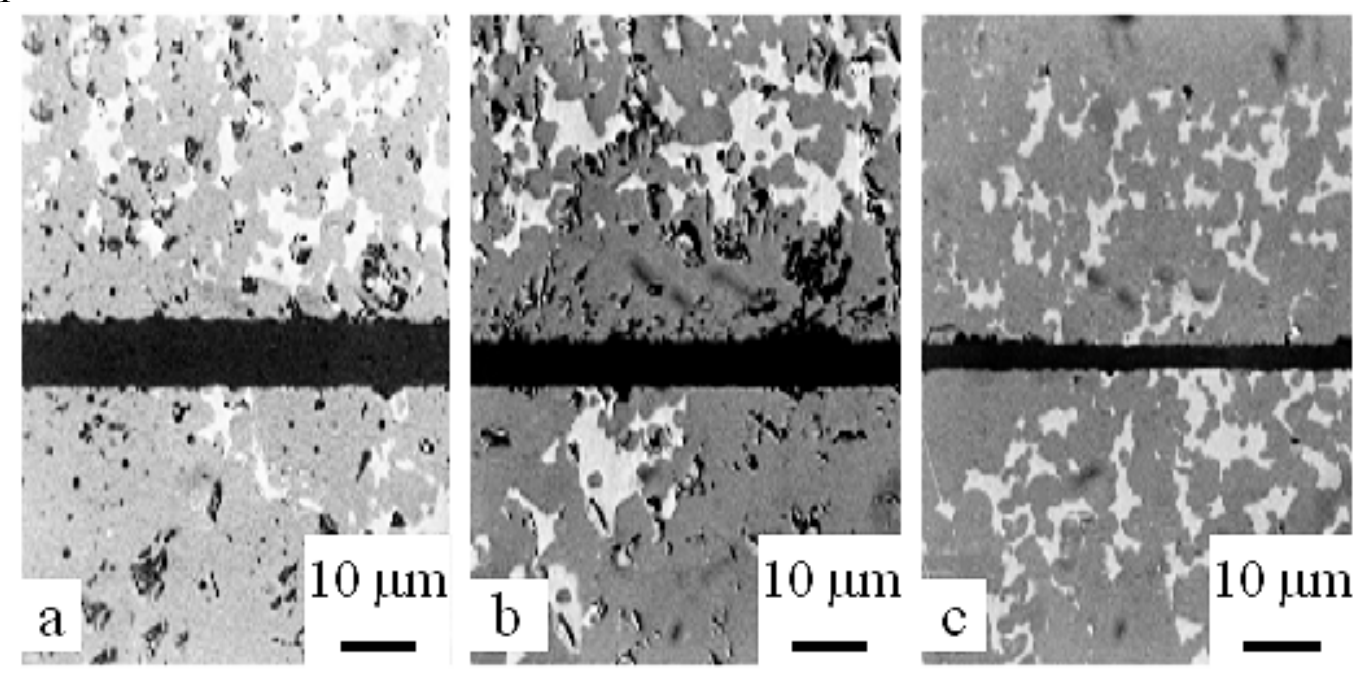

Figure 3. Optical micrographs of the joint region of $\mathrm{SiSiC}$ samples joined at different temperatures: a) $800^{\circ} \mathrm{C}$; b) $1000^{\circ} \mathrm{C}$; c) $1200^{\circ} \mathrm{C}$

However, in the case of the $\mathrm{SiC} / \mathrm{SiC}_{\mathrm{f}}$ ceramic composite, the shear strength for the joint was not satisfactory, being on the average below $4 \mathrm{MPa}$ [11]. The low strength was attributed to the presence of defects in the joining layer arising from shrinkage and densification of the preceramic polymer, concentrated within the non-flat areas of the composite surface. $2 \mathrm{D}$ and $3 \mathrm{D}$ composites, because of their different surface morphology, gave different results, with a lower strength for the samples possessing the most strongly textured surface (3D) [11].

The introduction of filler powders increased the strength and somewhat reduced the scattering of the data, due to the great decrease of shrinkage during pyrolysis, and the effective reduction defects in the layer. Average shear strength as high as $17.4 \pm 3.5 \mathrm{MPa}$ was achieved when using an active filler $\left(\mathrm{Al}_{88} \mathrm{Si}_{12}\right.$ powder), that melts before reacting to give ceramic products, thus ensuring a more homogeneous distribution of the reaction products within the joining layer, instead of concentrating them in scattered particles. By reinfiltration of these joints using a diluted polymer solution without additives (up to 4 times), followed by further pyrolysis at $1200^{\circ} \mathrm{C}$, the shear strength strongly increased, due to the reduction of porosity within the joint itself (see Fig. 5). The difference in effectiveness between inert and active fillers might be related to the different distribution of the filler within the joining layer after processing (scattered particles in the first case, homogeneous distribution of reaction products in the second one). 

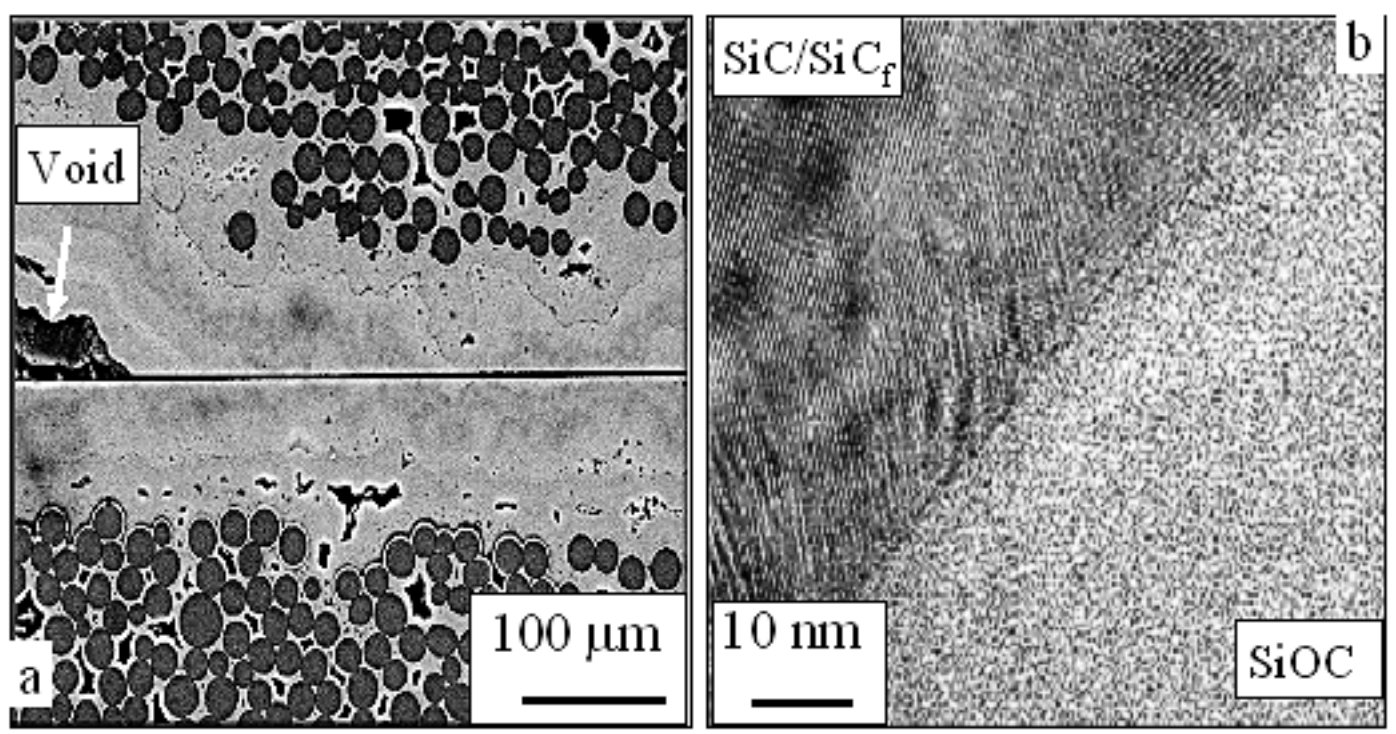

Figure 4a. SEM micrograph of a joint $\left(\mathrm{SiC} / \mathrm{SiC}_{\mathrm{f}}\right)$

Figure 4b. HREM micrograph of a joint $\left(\mathrm{SiC} / \mathrm{SiC}_{\mathrm{f}}\right)$

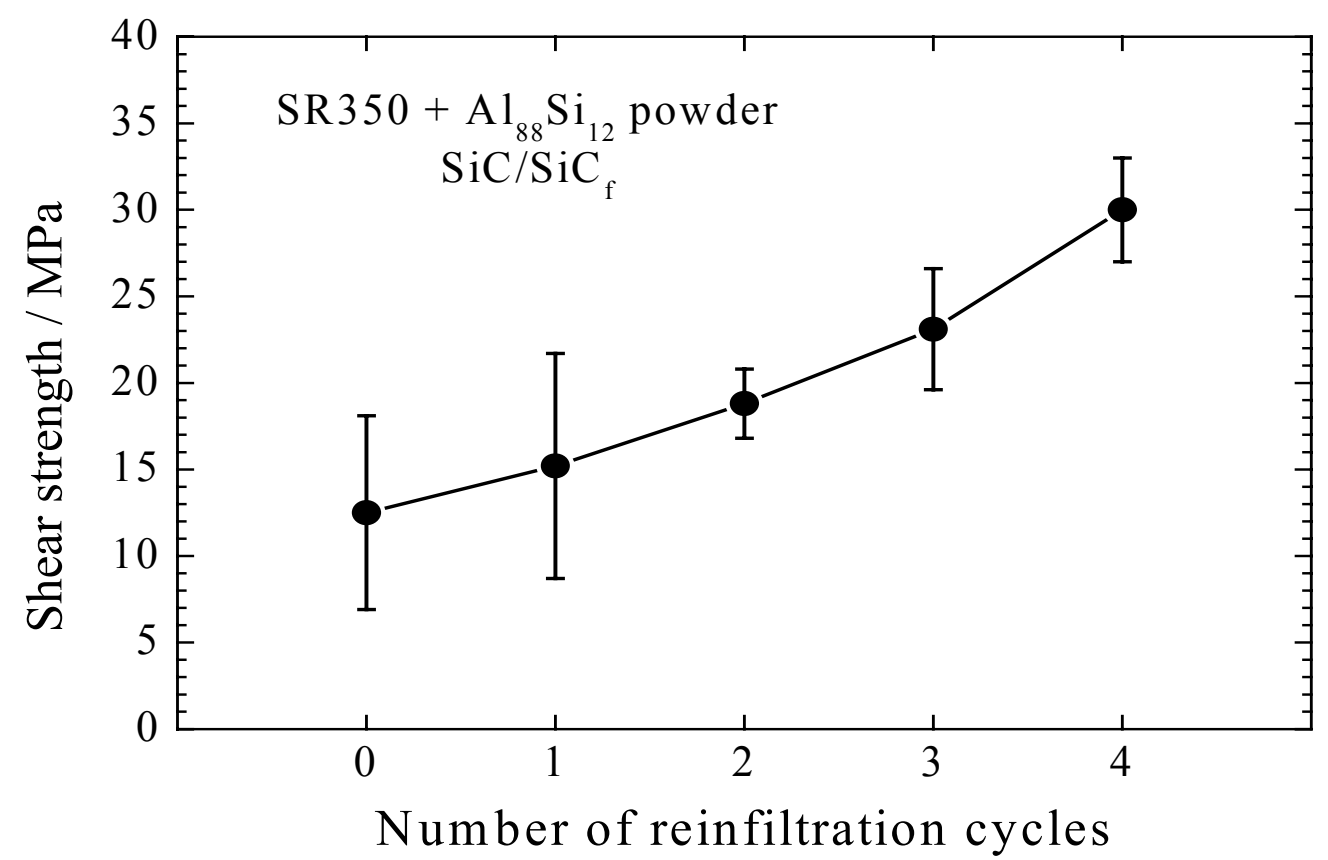

Figure 5. Shear strength as a function of the number of reinfiltration cycles, for joints between 3D composites obtained using SR350 and $\mathrm{Al}-\mathrm{Si}$ powder $\left(\mathrm{SiC} / \mathrm{SiC}_{\mathrm{f}}\right)$

$\mathrm{SiC} / \mathrm{SiC}_{\mathrm{f}}$ composite specimens were also joined using a polycarbosilane (AHPCS) loaded with a $\mathrm{SiC}$ powder mixture (monomodal or a bimodal in size). Both 
conventional and microwave hybrid pyrolysis of the preceramic polymer slurry produced $\mathrm{SiC} / \mathrm{SiC}_{\mathrm{f}}$ joints that were continuous and with similar fracture strength $(<6 \mathrm{MPa})$. In general, the microwave hybrid heated specimens produced a coarser, grainier microstructure in the ceramic material, a slightly lower fracture stress and a higher Weibull modulus, both decreasing with increasing temperature. These results are consistent with a greater degree of conversion of the amorphous covalent ceramic pyrolysis product to crystalline $\mathrm{SiC}$ by the microwave hybrid heating process [17].

The importance of morphology of the surface in the case of joining ceramic composite samples (sandwich joint) was demonstrated using a slurry of liquid AHPCS and SiC powder (weight ratio $\mathrm{SiC} / \mathrm{AHPCS}=2.5$ ) and repeating the joining procedure on the same surface of the sample for a number of times, after detaching the joined samples by mechanical testing. Indeed, the shear strength of joined $3 \mathrm{D} \mathrm{SiC} / \mathrm{SiC}_{\mathrm{f}}$ ceramic composite specimens increased considerably with decreasing surface roughness of the substrate (Fig. 6b). Microscopy and profilometry data show that each iteration of the polishing and testing procedure produced a smoother surface (Fig. 6a), because of the effective filling of the surface voids by the joining material ceramic residues. Since the surfaces that were joined were polished with 400 grit paper prior to each joining step, the change in surface morphology is due solely to the filling of the large inter-bundle pores present in the composite substrates, leading to a reduction in the flaw size or the number of flaws. It is also possible, however, that the surface treatment increased the contact area between the joint and the substrate and decreased the effective stress in the joining material (for the same load). Since mechanical interlocking can play an important role in the development of strong joints, a controlled study of the influence of surface treatment and contact area is therefore recommended.

Although low values of strength were obtained for joints between $\mathrm{SiC} / \mathrm{SiC}_{\mathrm{f}}$ composites, which were unlike joints between monolithic ceramics and did not exhibit tolerable values of strength, we must point out that most of the work was carried out with the aim of satisfying criteria relevant to using the materials in a nuclear fusion reactor. Thus, very stringent limitations were enforced on the joining material and processing technique, such as the use only of low activation constituents (such as $\mathrm{Si}, \mathrm{C}, \mathrm{O}$ ), and a processing temperature lower than $1200^{\circ} \mathrm{C}$, in order not to damage the fibers of the composites used in the experiments.

It is quite possible that the use of novel ceramic composite materials, such as the ones obtained with the NITE process [18] possessing a very different surface morphology from the current ones, the adoption of novel generation ceramic fibers allowing a much higher service temperature (and thus higher processing temperature), or the refinement of processing methods would allow successful joining of ceramic composites using preceramic polymers. 


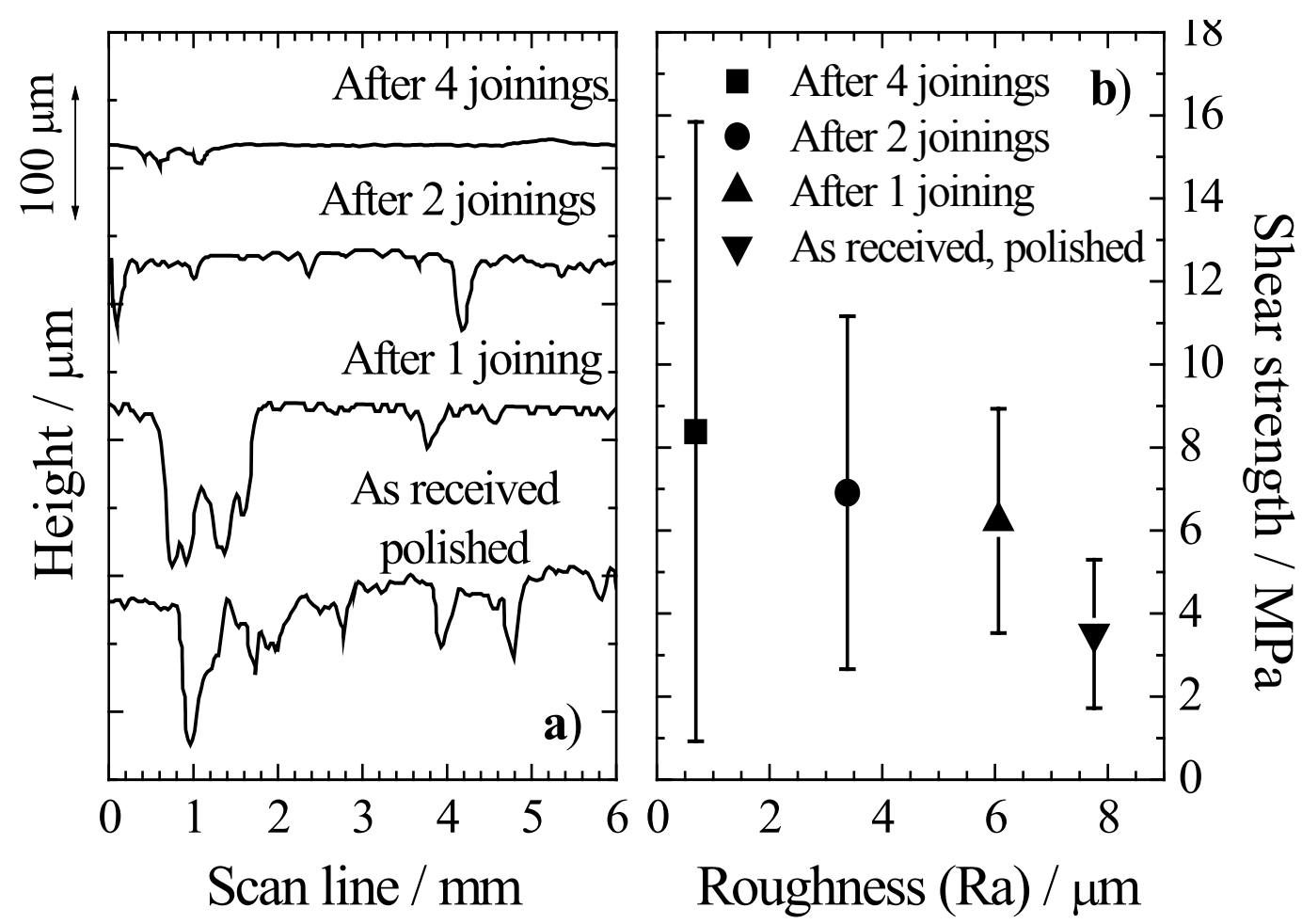

Figure 6. a) stylus profilometer line-scan patterns for $3 \mathrm{D} \mathrm{SiC} / \mathrm{SiC}_{\mathrm{f}}$ ceramic composites; $b$ ) shear strength $(\mathrm{MPa})$ as a function of surface roughness

From the data presented, which cover various materials and experimental conditions, it is evident that the joint strength depends simultaneously on a large number of variables (composition and characteristics of the joining material, processing schedule, surface morphology of the specimens, preparation of the surface, testing methodology, ...) whose optimization requires a considerable experimental work. Furthermore, when joining ceramics using preceramic polymers, some issues specific to this technology have to be considered. These include: the preceramic precursor's yield, the setting characteristics, the rheology of the joining mixture, the amount and type of possible fillers, the maximum processing temperature, dwelling time, heating rate and the pyrolysis atmosphere. In particular, a critical area that still requires improvement in order to render more widely applicable this promising joining technology is the reduction of the shrinkage associated with the polymer-to-ceramic conversion of the precursors, resulting in the creation of strength-limiting flaws caused by stresses developing in the joint layer, and in the difficulty of producing hermetic seals (especially when joining rough surfaces). 


\section{CONCLUSIONS}

Joints with up to $80 \%$ of the strength obtained by the best available joining methods $[3,19,20,21]$ have been obtained using preceramic polymer precursors as adhesives. Using preceramic polymers and fillers it is indeed possible to join SiC-based ceramics in a way that is rather simple, versatile and economical from the processing point of view. However, while the joining of monolithic ceramics has been successful, joining of ceramic composites, due to the morphology of the surfaces, has not resulted in joints with values of high strength. In the latter case, the use of fillers and, often, a careful preparation of the sample, are recommended.

\section{ACKNOWLEDGEMENTS}

Part of this work was carried out in the frame of the E.C. Fusion Technology Long-Term Programme - Materials 1995/98 SDS 3.1.1 and Advanced Materials 1999/02 ADV 1.2.1.

\section{REFERENCES}

${ }^{1}$ R.H. Jones, L.L. Snead, A. Kohyama and P. Fenici, "Recent advances in the development of SiC:SiC as a fusion structural material," J.Nucl.Mater., 258-263 1546-1550 (1998)

${ }^{2}$ A.C. Ferro and B. Derby, "Liquid phase bonding of siliconized silicon carbide," J.Mater.Sci. 30 6119-35 (1995)

${ }^{3}$ T. Iseki, “ Joining of SiC ceramics”; pp. 239-63 in Silicon Carbide Ceramics 1, edited by S. Somiya and Y.Inomata, Elsevier Applied Science, London, 1991

${ }^{4}$ S. Yajima, K. Okamura, T. Shishido, Y. Hasegawa and T. Matsuzawa, "Joining of $\mathrm{SiC}$ to $\mathrm{SiC}$ using polyborosiloxane," Am.Ceram.Soc.Bull., 60253 (1981)

${ }^{5}$ A. Donato, P. Colombo and M.O. Abdirashid, "Joining of $\mathrm{SiC}$ to $\mathrm{SiC}$ using a preceramic polymer"; pp. 471-36 in High-Temperature Ceramic-Matrix Composites I: Design, durability and performance, Ceramic Transactions Vol. 57. Edited by A.G. Evans and R. Naslain, The American Ceramic Society, Westerville OH, 1995

${ }^{6}$ I. Ahmad, R. Silberglitt, Y.L. Tian and J.D. Katz, "Microwave joining of SiC ceramics and composites"; pp 455-50 in Microwaves: Theory and Application in Materials Processing IV, Ceramic Transactions 80. Edited by D.E. Clark, W.H. Sutton and D.A. Lewis. The American Ceramic Society, Westerville, OH, 1997

${ }^{7}$ W.J. Sherwood, C.K. Whitmarsh, J.M. Jacobs and L.V. Interrante, “ Joining Ceramic Composites Using Active Metal/HCPS Preceramic Polymer Slurries," Cer.Eng.Sci.Proc., 18 177-84 (1997)

${ }^{8}$ I.E. Anderson, S. Ijadi-Maghsoodi, Ö. Ünal, M. Nostrati and W.E. Bustamante, pp. 25-40 in Ceramic Joining, Ceramic Transactions 77. Edited by 
I.E. Reimanis, C.H. Henager and A.P. Tomsia. The American Ceramic Society, Westerville OH, 1997

${ }^{9}$ E. Pippel, J. Woltersdorf, P. Colombo and A. Donato, "Structure and composition of interlayers in joints between SiC bodies," J.Europ.Ceram.Soc., 17 1259-65 (1997)

${ }^{10}$ P. Colombo, V. Sglavo, E. Pippel and J. Woltersdorf, "Joining of ReactionBonded Silicon carbide using a preceramic polymer," J.Mater.Sci., 33 2409-16 (1998)

${ }^{11} \mathrm{P}$. Colombo, B. Riccardi, A. Donato and G. Scarinci, "Joining of $\mathrm{SiC} / \mathrm{SiC}_{\mathrm{f}}$ ceramic matrix composites for fusion reactor blanket applications," J.Nucl.Mater., 278 127-35 (2000)

${ }^{12} \mathrm{~J}$. Zheng and M. Akinc, "Green state joining of $\mathrm{SiC}$ without applied pressure," J.Am.Ceram.Soc., 84 2479-82 (2001)

${ }^{13}$ C.A. Lewinsohn, P. Colombo, I. Reimanis, Ö. Ünal, "Stresses Arising During Joining of Ceramics Using Preceramic Polymers" J.Amer.Ceram.Soc., 84 2240$45(2001)$

${ }^{14}$ P. Greil, “Active-Filler-Controlled Pyrolysis of Preceramic Polymers," J. Am. Ceram. Soc., 78 835-48 (1995)

${ }^{15}$ R. Riedel, "Advanced Ceramics from Inorganic Polymers"; pp. 1-50 in Materials Science and Technology, A comprehensive treatment. Vol. 17B Processing of Ceramics, Part II, R. J. Brook ed. VCH Wurzburg, Germany, 1996

${ }^{16}$ H.P. Kirchner, J.C. Conway, Jr. and A.E. Segall, "Effect of joint thickness and residual stresses on the properties of ceramic adhesive joints: I, Finite element analysis of stresses in joints, J.Am.Ceram.Soc., 70 104-09 (1987)

${ }^{17}$ G.A. Danko, R. Silberglitt, P. Colombo, E. Pippel and J. Woltersdorf, "Comparison of microwave hybrid and conventional heating of preceramic polymers to form silicon carbide and silicon oxycarbide ceramics," J.Amer.Ceram.Soc., 83 1617-25 (2000)

${ }^{18}$ A. Kohyama, "Overview of CREST-ACE Program for $\mathrm{SiC} / \mathrm{SiC}$ Ceramic Composites and Their Energy System Applications"; in Proceedings of CRESTInternational Symposium on $\mathrm{SiC} / \mathrm{SiC}$ Composite Materials $\mathrm{R} \& \mathrm{D}$ and Its Application to Advanced Energy Systems, May 20-22, 2002, Kyoto, Japan

${ }^{19}$ B.H. Rabin, and G.A. Moore, "Joining of SiC-Based Ceramics by Reaction Bonding Methods," J. Mat. Synth. \& Proc., 1 [3] 195-201 (1993)

${ }^{20}$ M. Singh, "A Reaction Forming Method for Joining of Silicon CarbideBased Ceramics," Scripta Mater., 37 [8] 1151-1154 (1997)

${ }^{21}$ C.A. Lewinsohn, R.H. Jones, M. Singh, T. Nozawa, M. Kotani, Y. Katoh, and A. Kohyama, "Silicon Carbide Based Joining Materials for Fusion Energy and Other High-Temperature, Structural Applications,"Ceram. Eng. \& Sci.Proc., 22 [4] 621-625 (2001) 